\title{
The View of Intercultural Competence in the Context of Communicative-Based in English Language Teaching
}

\author{
Absharini Kardena ${ }^{1}$, Hamzah $^{2}$, Hermawati Syarif ${ }^{3}$, M. Zaim ${ }^{4}$ \\ \{absharinikardena@yahoo.co.id ${ }^{1}$,hamzahhs@yahoo.com ${ }^{2}$, hermawati_sy@yahoo.com ${ }^{3}$, \\ mzaim_unp@yahoo.com ${ }^{4}$ \} \\ Faculty of Tarbiyah and Teacher Training Institut Agama Islam Negeri (IAIN) Bukittinggi Indonesia ${ }^{1}$ \\ English Education Section of Post Graduate Program Universitas Negeri Padang, Indonesia ${ }^{2,3,4}$
}

\begin{abstract}
. this article is a kind of library research which discusses the importance of intercultural competence in communication by using English. As intercultural competence is a part of communicative competence, it is categorized significant to involve this competence in English teaching classroom since English students are expected to be able to communicate fluently, correctly and acceptable. Thus, the students should be provided with such abilities that can encourage them to be better in English.
\end{abstract}

Keywords.intercultural, competence, spoken, communication

\section{Introduction}

As one of important competences in English teaching, intercultural competence is categorized as one of vital competences that should be acquired by English students. Intercultural competence which is commonly known as IC is a competence that involves students to consider their cultural background and cultural that embedded on the language used, which is English, at this case. The ability of students in producing language by considering IC is significantly important since it influences how the language produced. As stated by Council of Europe in standard for foreign language learning (2001) that the goals of learning foreign language is not merely on acquiring language structure, but it consists of 5 C's (communications, cultures, connections, comparisons, and communities)[1]. Thus, it can be argued that learning English nowadays is not simply about producing sentences that are grammatically correct, but considering the appropriateness of those sentences based on mutual understanding among the language users. By considering the importance of acquiring intercultural competence in English, the students should be provided by some principles that lead them to know how using English appropriately and accurately. In some cases, the intercultural competence is being one of causes of misunderstanding in communication. Students' lack competence in intercultural lead the problems during communication. It happens because the students do not know how to use English by considering the culture embedded on 
English itself. In other words, mostly students use English not involving the culture of English, but use their own culture (Indonesian culture or even district culture). It causes misunderstanding because somehow English cannot be understood whenever the users, in this case they are the students, do not apply the knowledge of intercultural competence. In fact, there are some sentences or expressions that should follow the culture contained in English. Thus, whenever the students do not do it, the students cannot produce understandable sentences during their communication. The understandable sentences can be produced when the students have knowledge about intercultural and can apply it in form of their intercultural competence. Thus, it is important to discuss what intercultural competence is and its position in communicative -based English teaching.

\section{Communicative Competence In Language Learning}

In the context of teaching English as a foreign language, communicative competence has been known widely by experts and even language practitioners. The term communicative competence is commonly linked to the way the students acquire English as a foreign language by considering the main function of the language that is for communication. The main premise in communicative competence is how language used by considering not only the structure of the language but also its function in real life.

Communicative competence is, then, a part of language competences that requires the students to consider the communicative aspects in using language. In other words, the students are demanded to not only focus on producing language that concerns on the linguistics aspect only, but also the appropriateness to a given context. Shortly, the language users, in this case the students of English as a foreign language, should apply both linguistics and functional aspects in language use[2]. The development of communicative competence was started by pointing out that language production must not merely about using appropriate linguistics competence only. The students as the language users, in fact, cannot use the language in their real life even they know the linguistics aspect or the grammar rules so well. It directs the attention to take a step moving from the linguistic competence only into a new competence that deals with the real use of language, as nowadays known as communicative competence. At this point, Martin in [3] points out how important to highlight the communicative and functional aspect during language production[3]. He claims that is surely important for language user "to communicate functionally and interactively." He adds "... it is a dynamic concept based on the negotiation of meanings among the language users, which can be applied either to written or spoken modes of communication." This statement stresses the importance of negotiation meaning during communication as a part of interaction through language. It can be simplified that negotiation meaning is the key point in sharing ideas among language users that finally build the communication.

During the development of communicative competence, many experts have argued in defining and categorizing communicative competence. One of the common theories is proposed by Canale and Swain in [4]. They devide the communicative competence into four main components; grammatical competence, sociolinguistics competence, strategic competence and discourse competence[4]. Grammatical competence which is also named as linguistics competence include the knowledge related to lexicon, syntax and semantics; sociolinguistics competence focussing on the appropriateness of the communication and language production to the context in which they are used; strategic competence is a competence that deals with any 
strategies which can be applied to produce an effective communication; the last one is discourse competence which is concerned with the competence in developing sentences or utterances in well arrangement of ideas and good structuralized language produced. Those competences are interrelated each other during the communication, written and oral, so that it produces a comprehensible output of language production. Another is the idea from[4], [5], describing the components of communicative competence from another point of view. They divide the communicative competence into three main categories, namely, language competence, strategic competence and psycho-physiological competence[4], [5]. These three classifications show the way they categorize communicative competence.

Concerning language competence, it can be specified into organizational competence and pragmatic competence[4], [5]. In this sense, organizational competence discusses about grammatical competence that is focusing on the development of ability in using language grammatically correct and textual competence which comprises into the knowledge of cohesion and knowledge of rhetorical or conversation organization[5]. Moreover, in explaining the pragmatic competence, it can be divided it into two main parts; illocutionary and sociolinguistics competence. In other words, the pragmatic competence concerns on the language use[4], [5]. The other competence that differs between Canale and Swain's idea into Bachman and Palmer's is on the psycho-physiological competence. They argue that the psychophysiological competence influences the communicative function of a language since the production of the language is not only about setting and context but also the individual competence in analyzing the situation before producing the language[5].

The other theory related to the communicative language ability is proposed by the Council of Europe in Common European Framework of Reference for Language (2001). The council specifies the communicative language ability into 3 main competences; they are sociolinguistics competence, linguistics competence, and pragmatic competence[1]. The different exploration of these competences is placed on the pragmatic competence in which this competence is divided into 3 parts, included discourse competence, functional competence, and design competence. Discourse competence is dealt to language user's knowledge in arranging and organizing the ideas produced as their sentences or utterances. Discourse competence is categorized into topic/ focus, given/ new, natural sequencing, cause/ effect, and ability to structure and manage discourse in terms of thematic organization, coherence and cohesion, logical ordering, style and register, rhetorical effectiveness, the co-operative principle. Moreover, the functional competence is concerned on the way to perform the communicative function of the language while design competence focuses on sequence according to interactional and transactional schemata.

Those mentioned views are basically similar saying the concept of communicative competence with different terms. Generally, communicative language ability or it is also called as communicative competence involved at least 5 competences; they are linguistics competence, sociolinguistics competence, strategic competence, psycholinguistics competence and discourse competence.

\section{Intercultural Competence In English language Teaching}

In recent years the concept of intercultural competence has started to spread in the field of English language teaching and learning. Intercultural competence that is also known as intercultural communicative competence (ICC) is one of language competences that decide 
how good a language learner is. This competence is a kind of competence that lead the students to interconnect among their own cultures to the target cultures learned in order to build a strong concept of different cultures. The knowledge of these different cultures is used for the development of cultural awareness while avoiding any stereotyping of different cultures. In other words, the intercultural competence is a base line for the students to recognize, be aware and tolerate any cultural values from other languages.

Intercultural competence is based on the concept of culture itself. In fact, many experts argue that culture should not be seen as a wide as culture in general concept. There must be a limitation of culture that can be taught in the classroom. According for Furstenberg, "...culture is a highly complex, elusive, multilayered notion that encompasses many different and overlapping areas and that inherently defies easy categorization and classification"[6]. Based on definition of culture, it can be simplified that culture is a complex area that involves lots of categorization and classification. In other case, Lazar explains that the teacher should be able to classify which culture that is belong to culture in language education[7]. In a more complex explanation, [7] divides culture into two main categories, Culture with big $\mathrm{C}$ and culture with little c. Culture with big $\mathrm{C}$ is belong to civilization, such arts and literatures while culture with little $\mathrm{c}$ is belong to cultural dimension of language. This little $\mathrm{c}$ of culture is discussed lots by [8] in which he states that culture in education context refers to communication styles, beliefs, values, attitudes and perceptions. In strengthens the idea that culture that should be taught to students is simply the one that can influence their language production since it is interconnected to the knowledge of beliefs, values, and communication styles. In this case, [9] argues that cultural learning is a natural process happened in human life in order to socialize with their environment. Furthermore, he adds that there are two types of cultural learning; enculturation and acculturation. Enculturation is a process of culture learning by the native through grows up in their own environment. This process commonly results a strong perception that their own culture is more powerful than other cultures. It might occur since they only socialize and grow up on their own environment and strictly apply the culture during their daily life. In other side, acculturation refers to a process of culture learning in which the students consciously learn new culture. By considering the concept of culture above, the notion of cultural learning in EFL context is categorized important. It leads to the development and improvement of intercultural competence in language class. It cannot be denied that intercultural competence should be included in teaching and learning processes. Moreover, building intercultural sensitivity in order to build students' intercultural competence involves many steps that should be faced by the teachers. The Developmental model of intercultural sensitivity [10] reveals the process of accumulation of experience and changes in the attitudes. The stages of intercultural sensitivity development are presented as well in the following model (see Fig.1).

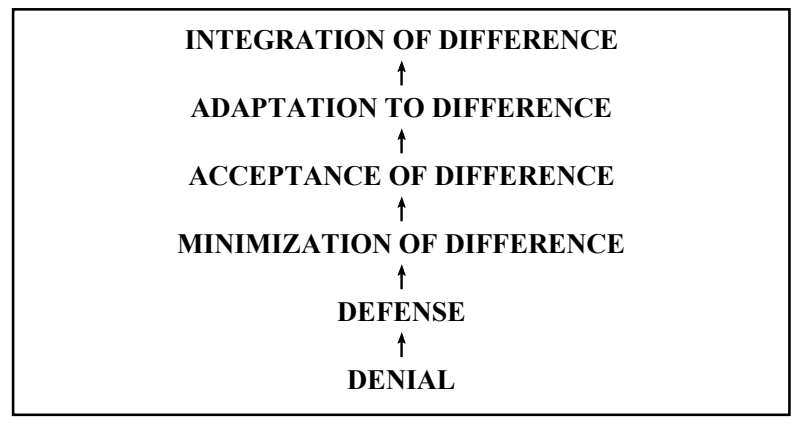


Fig.1. The stages of intercultural sensitivity development [10]

In developing students' intercultural competence, students become the centre of the teaching and learning process and the role of teachers is focused on encouraging autonomous and independent learning skills in their students. Thus, learner-centered instruction paradigm is applied in teaching intercultural competence to support the students in encouraging themselves to participate actively in the classroom. By considering the implementation of learner-centered instruction for teaching intercultural competence, the teacher has a specific role in the classroom. According to [11], an educator has a role in developing intercultural competence. They state that a teacher is a promoter of multicultural perspective. In doing this role, the teacher at least has four main tasks; helps the students to tolerant for different cultures, to respect to the diverse culture, to avoid stereotyping others, and develop various materials for cross-cultural communication. Besides, [12]strengthens that a language teacher has a role to mediate between native language and target language cultures to help learners achieve language learning goals. Thus, the teachers should have intercultural competence including cultural knowledge, attitudes and competencies and skills. In a more detail study, intercultural competence is tied strongly to such discourse competence. It is Kaplan who firstly and widely known as an expert who clearly propose a cultural thought pattern based on intercultural education. [13] states cultural differences highly relate to rhetoric that supplies the key to the difference in teaching approach." In a mode detail explanation he explains

...Rhetoric is a mode of thinking or a mode of "finding all available means" for the achievement of a designated end. Accordingly, rhetoric concerns itself basically with what goes on in the mind rather than with what comes out of the mouth... Rhetoric is concerned with the factors of analysis, data gathering interpretation and synthesis... what we notice in the environment and how we notice it are both predetermined to a significant degree by how we are prepared to notice this particular type of object... cultural anthropologists point out that given acts and objects appear vastly different in different cultures, depending on the values attached to them. Psychologists investigating perception are increasingly insistent that what is perceived depends upon the observer's perceptual frame of reference.

According to [13], the cultural thought can be patterned based on intercultural education In general, he divides it into 5 groups; consist of English, Semitic, Oriental, Romance, and Russian. The following chart shows the cultural though patterns in intercultural education:

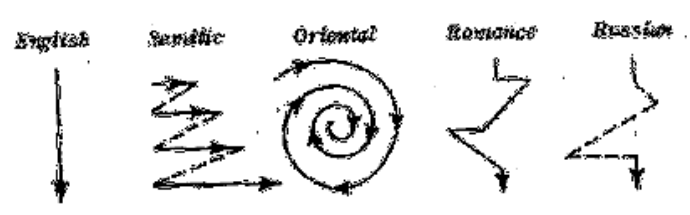

Fig 2. Cultural though Patterns in Intercultural Education

Figutre. 2 can be explained as follows: 
a. North American (English) argumentative writing is linear, direct and to the point, with the thesis statement/claim at the beginning of the argument, and supporting arguments arranged hierarchically.

b. Semitic argumentative writing (Jewish, Arabic, Armenian) presents the argument in parallel propositions, or embedded in stories, not in hierarchical progression.

c. Oriental (Asian) argumentative writing approaches the argument in a circular, respectful, indirect, non-assertive, but authoritative way.

d. Romance (and German) argumentative writing favor a digressive style that requires readers to follow the argument to its conclusion.

e. Russian argumentative writing follows the Romance model, but with more freedom for dividing the pieces of the argument as the author proceeds to the conclusion

Kaplan's model of "contrastive rhetoric" is a generic typology of cultural writing patterns, not an endorsement of one cultural style over against another. However, language teachers have sometimes used this typology to privilege the American academic writing style as the superior rhetoric and to render the others inferior to it.

In fact, in more recent studies, this kind of contrastive rhetoric model proposed by Kaplan were criticism by linguistics experts. As stated by [14], there are few critics offered to Kaplan's model. It has been criticized on the grounds that it is too etnocentric and privileging the writing of native English speakers; it ignores the educational and students' developmental factors'; it rules out the possibility of univerxsality in though pattern; it was based on intuition rather than on scientific work; it concerns more with the writing product than writing process; it neglects a range of appropriate styles within the same culture; it considers L1 interference as a hindrance in $\mathrm{L} 2$ writing.

Furthermore, in recent years this model has been critiqued for its tendency toward cultural caricature and its failure to reflect the broader multiculturalism and linguistic diversity that international students draw upon when they write in a new language. However, many students continue to find these models useful for illuminating rhetorical differences between writing cultures and for developing their own cultural writing models when Kaplan's categories do not fit their own contexts. Besides, Kaplan's model is influential power in the field of writing pedagogy. It has had an immense impact on the teaching of writing, both for ESL and EFL context that stimulated how writing differs across cultures [14].

By considering the importance of intercultural competence as one of linguistics aspects, it cannot be denied that this competence should be integrated as one of indicators to evaluate students' language proficiency. Learning intercultural concept does not meet to reject the native culture and adopt all the target cultures, but it is more on learning to respect any diversity occurred among different cultures. Besides, it aims to help the students to notice the acceptable language produced while also paying attention the rules of language and the fluency. At the end, it is expected that the students can use the language well and understandable.

\section{Conclusion}

Based on the discussion of theories above, it can be stated that intercultural competence is one of influential competences that should be involved in English language teaching and learning. Ignoring this competence may impact on the students competence in producing language that is accurate, fluent and acceptable. Besides, acquiring this competence may help 
the students to avoid any stereotyping and misunderstanding during communication. Thus, it is expected that English teachers may always involve intercultural competence while building up students' ability in communication by using English.

\section{References}

[1] C. of Europe, "Common European Framework Of Reference For Languages: Learning, Teaching, Assessment."

[2] D. . Hymes, On communicative competence. 1972.

[3] F. Trujillo Sáez, "Towards Interculturality Through Language Teaching: Argumentative Discourse," vol. 25, pp. 103-120, 2002.

[4] L. Bachman, Fundamental considerations in language testing. Oxford: Oxford University Press, 1990.

[5] A. Bachman, lyle and Palmer, Language Testing in Practice. Oxford: Oxford University Press, 1996.

[6] G. Furstenberg, "Making culture the core of the language class: Can it be done?.," Mod. Lang. Journal, vol. 94, no. 2, pp. 329-332, 2010.

[7] and M. K. Lazar, Ildiko, Developing and Assessing Intercultural Communicative Competence. Kapfenberg: European Centre for Modern Language, 2007.

[8] W. Brembeck, "The Development and Teaching of a College Course in Intercultural Communication," in Readings in Intercultural Communication, Pittsburgh: SIETAR Publications, 1977.

[9] L. Damen, Culture learning: The fifth dimension in the language classroom. Mass: Addison Wesley Publishing Company, 1987.

[10] M. J. Bennett, "Towards ethnorelativism: A developmental model of intercultural sensitivity," Educ. Intercult. Exp., vol. 2, pp. 21-71, 1993.

[11] H. and Y. K. Kojima, "Teacher roles in learner-centered communicative EFL instruction," 2005. [Online]. Available: http://repository.ul.hirosakiu.ac.jp/dspace/bitstream/10129/544/1/AN00211590_94_59.pdf. [Accessed: 04-Jun-2012].

[12] D. Atay, "The Role of Intercultural Competence in Foreign," Inonu Univ. J. Fac. Educ., vol. 10, no. 3, pp. 123-135, 2009.

[13] R. . KAPLAN, "Cultural thought patterns in inter-cultural education," Lang. Learn., vol. 16, no. 1, pp. 11-25, 1966.

[14] S. Sugiharto, "Criticisms to the CR,” J. Asia Tefl, vol. 4, no. 1, pp. 107-124, 2007. 